\title{
Influence of melatonin on IL-1Ra gene and IL-1 expression in rats with liver ischemia reperfusion injury
}

\author{
HONG ZHOU, CHUNHUI JIANG, LEI GU, YE LIU, LONGCI SUN and QING XU \\ Department of Gastrointestinal Surgery, Ren Ji Hospital, School of Medicine, \\ Shanghai Jiao Tong University, Shanghai 200127, P.R. China
}

Received June 9, 2015; Accepted January 4, 2016

DOI: $10.3892 /$ br.2016.645

\begin{abstract}
The aim of the present study was to explore the influence of melatonin (MT) on rats with liver ischemia reperfusion injury (IRI) and its mechanism. A total of 66 male Sprague-Dawley rats were randomly divided into 3 groups: i) Normal control group, ii) ischemia reperfusion group (IR group) and iii) melatonin treatment group (MT group). Rats in the MT group were administered an intraperitoneal injection of MT $(10 \mathrm{mg} / \mathrm{kg}, 1 \mathrm{ml})$ at 70 and $35 \mathrm{~min}$ before ischemia, early reperfusion, and 1 and $2 \mathrm{~h}$ after reperfusion, respectively. Blood was removed at the normal time-point (prior to any processes), $35 \mathrm{~min}$ before ischemia, 2, 4, 8 and $24 \mathrm{~h}$ after reperfusion. Subsequently the rats were sacrificed. The pathological changes of liver tissues, interleukin-1 receptor antagonist (IL-1Ra) gene and IL-1 expression levels were detected. There were no evident differences between the immediate reperfusion and $2 \mathrm{~h}$ IR group and MT group. The liver structure injury of the 4,8 and $24 \mathrm{~h}$ MT groups were improved to various differences compared to the corresponding IR group; liver IL-1 $\beta$ of the MT group at 35 min after ischemia, and 2, 4, 8 and $24 \mathrm{~h}$ after reperfusion was evidently lower than that of the IR group $(\mathrm{P}<0.05)$; IL-1Ra mRNA expression in the $2 \mathrm{~h}$ MT group was higher compared to the $2 \mathrm{~h}$ IR group by 4.85 -fold; and IL-1Ra mRNA expression in the $4 \mathrm{~h}$ MT group was higher compared to the $4 \mathrm{~h}$ IR group by 9.34-fold. Differences between two groups at other time-points were <2-fold. In conclusion, MT can upregulate IL-1Ra gene expression by reducing generation of IL-1 thus reducing IRI.
\end{abstract}

\section{Introduction}

Hepatic portal occlusion (HPO) is one of the commonly used methods to control intraoperative bleeding; however, serious

Correspondence to: Mr. Qing Xu, Department of Gastrointestinal Surgery, Ren Ji Hospital, School of Medicine, Shanghai Jiao Tong University, 1630 Dongfang Road, Shanghai 200127, P.R. China E-mail: renjixuqing@163.com

Key words: melatonin, ischemia reperfusion injury, interleukin-1 receptor antagonist gene, interleukin-1 ischemia reperfusion injury (IRI) often occurs when the flow regains. Present study on brain, heart, kidney, retina and other tissues shows that a large number of free radicals are produced during IRI when endogenous radical scavengers are not in abundance, causing cell damage. Therefore, increasing attention in liver surgery has focused on identifying effective drugs to alleviate liver function damage in IRI and improve the postoperative survival rate.

Melatonin (MT) is a type of neural endocrine hormone secreted by the pineal gland, with antioxidant, anti-toxic, anti-stress and anti-inflammatory effects $(1,2)$. Studies found that MT has a protective role in IRI of brain, heart, kidney and retina; however, its protective role in hepatic IRI and its mechanism remain to be elucidated. The present study aimed to investigate whether MT can effectively reduce the HPO and the subsequent hepatic IRI and its action mechanism.

\section{Materials and methods}

Experimental animals and grouping. A total of 66 healthy male Sprague-Dawley rats were purchased from the Experimental Animal Department, Shanghai Jiaotong University (Shanghai Second Medical University, Shanghai, China). The rats (3-6 months; body weight, $220 \pm 30$ g) were divided into 3 groups: i) The normal control group (group N), ii) the ischemia reperfusion group (IR group) and iii) melatonin treatment group (MT group). Groups IR and MT were subdivided into 5 groups (n=6/each group): 35 min of ischemia, and 2, 4, 8 and $24 \mathrm{~h}$ reperfusion.

Main instruments and reagents

Main instruments. The main instruments used included animal surgical equipments, electronic balance, centrifuge (3K15; Sigma-Aldrich, St. Louis, MO, USA), RM2165 paraffin slicing machine, microscope (IX71; Leica Microsystems, Ltd., Milton Keynes, UK), polymerase chain reaction (PCR) and reverse transcription-quantitative PCR (RT-qPCR; ABI 7500 RealTime system; Applied Biosystems Life Technologies, Waltham, MA, USA).

Main reagents. MT (Sigma-Aldrich), the hematoxylin and eosin (H\&E) staining kit (Shanghai Beyotime Biological Technology Co., Ltd., Shanghai, China), interleukin-1 $\beta$ (IL-1 $\beta$ ) double antibody sandwich ABC-propidium iodide enzyme-linked immunosorbent assay (ELISA) (Shanghai 
Usen Biological Technology Co., Ltd., Shanghai, China) and RT reaction kit (Fermentas Co.; Thermo Fisher Scientific, Inc., Waltham, MA, USA) were used in the present study.

\section{Experimental method}

Modeling and processing. Pringle's method was used to totally block the first porta hepatis with a non-image small artery clip, thus causing complete occlusion of the portal vein, hepatic artery and common bile duct. The clip was unblocked 35 min after occlusion and the hepatic blood flow regained. Rats of the MT group were administered an intraperitoneal injection of MT (10 mg/kg, $1 \mathrm{ml})$ at 70 and $35 \mathrm{~min}$ before ischemia, early reperfusion, and 1 and $2 \mathrm{~h}$ after reperfusion, respectively $(3,4)$.

For each animal group, $1 \mathrm{ml}$ of blood was taken from the portal vein of the rat at the normal time-point (prior to any processes), $35 \mathrm{~min}$ before ischemia, 2, 4, 8 and $24 \mathrm{~h}$ after reperfusion (6 rats at each time-point). Subsequently, the blood was set in sterile pyrogen-free EP tubes for $20 \mathrm{~min}$ and centrifuged at 4,000 $\mathrm{x} \mathrm{g}$ for $10 \mathrm{~min}$. Serum was separated and stored at $-30^{\circ} \mathrm{C}$ until required for analysis. In total, $1 \mathrm{~g}$ of liver tissue was washed by physiological saline $\left(0^{\circ} \mathrm{C}\right)$ and stored in a liquid nitrogen tank for measurement. A total of $1 \mathrm{~g}$ of the liver tissue was fixed with $10 \%$ formaldehyde solution for analysis.

Pathology inspection of the liver tissue. Liver tissue was fixed with $10 \%$ formaldehyde. Following conventional paraffin section and H\&E staining, the pathological changes of the liver were observed under microscopy.

Serum IL-1 $\beta$ expression by ELISA. The anti-mouse IL-1 $\beta$ single antibody (cat. no. ab2105; Abcam, Cambridge, UK) was used to cover the ELISA plate. IL-1 $\beta$ of the standard and sample was combined with the single antibody. The biotinylated antimouse IL-1 $\beta$ antibody was added to form an immune complex, which was connected to the plate. Horseradish peroxidaselabeled streptavidin was combined with biotin. The enzyme substrate OPD was added and a yellow color was produced. The reaction was terminated when liquid sulfuric acid was added and the color became dark. The optical density (OD) value was measured at $492 \mathrm{~nm}$ and as the IL-1 $\beta$ concentration was positively correlated with the OD value, the IL-1 $\beta$ concentration in the specimen could be obtained by a standard curve.

Interleukin-1 receptor antagonist (IL-1Ra) gene expression by $R T-q P C R$. Total RNA was extracted and RNA was reverse transcribed into cDNA according to the manufacturer's protocol of the reverse transcription kit (Applied Biosystems Life Technologies). Real-time PCR primers were designed and synthesized by Takara Co. (Otsu, Japan) according to IL-1Ra (NM_022194) and rat 18S gene sequences. Amplification was carried out in accordance with the manufacturer's protocol. The sequences were as follows: Rat-18S-s, 5'-CGGCTACCACATCCAAGGAA-3'; rat-18S-a, 5'-GCTGGAATTACCGCGGCT-3'. The amplification conditions were: $95^{\circ} \mathrm{C}$ for $2 \mathrm{~min}, 95^{\circ} \mathrm{C}$ for $15 \mathrm{sec}, 60^{\circ} \mathrm{C}$ for $20 \mathrm{sec}$, $72^{\circ} \mathrm{C}$ for $20 \mathrm{sec}$, for a total of 37 cycles. The LightCycler (Roche Diagnostics Co., Indianapolis, IN, USA) was used for the amplification reaction and $\mathrm{Cq}$ value. The formula $\Delta \mathrm{C}_{\mathrm{q}}=\mathrm{C}_{\mathrm{q}}$ (IL-1Ra)- $\mathrm{C}_{\mathrm{q}}(18 \mathrm{~S})$ was used and relative expression of the IL-1Ra mRNA was $2^{-\Delta \Delta C t}$.

Statistical analysis. SPSS 10.0 (SPSS, Inc., Chicago, IL, USA) was used for the statistical analysis. Quantitative data are presented as mean \pm standard deviation. Analysis of variance was used to compare between groups. The Student-Newman-Keuls test was used for pairwise comparison between groups. $\mathrm{P}<0.05$ was considered to indicate a statistically significant difference.

\section{Results}

Pathological changes of liver tissue. Pathological sections of liver tissue specimens from every time-point after reperfusion were observed for morphology (Fig. 1). The results showed similar pathological changes between the IR group, $2 \mathrm{~h}$ IR group and MT group. Evident piecemeal necrosis and serious fusion necrosis were observed $4 \mathrm{~h}$ after reperfusion in the specimens of the IR group, while only piecemeal necrosis was observed in the MT group. Only piecemeal necrosis was observed in the MT group $8 \mathrm{~h}$ after reperfusion. No fusion necrosis was observed in each specimen. With the extension of reperfusion time, degeneration and necrosis degree of liver cells in the IR group and damage scope of hepatic cords were gradually expanded. A peak was reached at $24 \mathrm{~h}$ after reperfusion. Piecemeal necrosis and fusion necrosis were observed in each sample of the IR group; however, this change was not evident in the MT group. Piecemeal necrosis was observed in each sample of the MT group; however, fusion necrosis was not observed.

Examination results of $I L-1 \beta$. IL-1 $\beta$ values at each ischemic time-point of the IR and MT groups were higher than that of group $\mathrm{N}(\mathrm{P}<0.05)$. IL-1 $\beta$ values at $35 \mathrm{~min}$ of hepatic ischemia, $2,4,8$ and 24 h reperfusion of the MT group were significantly lower than that of the IR group $(\mathrm{P}<0.05)$. The results are shown in Table I.

Expression results of the IL-1Ra gene. The expression of NM_022194 (IL-1Ra) is shown in Fig. 2 and 18S is shown in Fig. 3.

Relative expression of $I L-1 R a$. Relative quantitative results showed that IL-1Ra mRNA expression in the $2 \mathrm{~h}$ MT group was higher compared to the $2 \mathrm{~h}$ IR group by 4.85 -fold and IL-1Ra mRNA expression in the $4 \mathrm{~h}$ MT group was higher compared to the $4 \mathrm{~h}$ IR group by 9.34 -fold. Differences between the two groups at other time-points were $<2$-fold. The IL-1Ra gene expression level was similar between the MT and IR groups at $24 \mathrm{~h}$ after reperfusion (Table II).

\section{Discussion}

Liver resection is a main treatment for a variety of liver diseases. The liver has a rich blood supply, so HPO is often adopted during surgery to reduce wound bleeding. However this method reduces the intraoperative bleeding while causing hepatic IRI.

During IR, hepatic neutrophil infiltration, release of inflammatory mediators and oxygen free radical formation are the important factors leading to liver damage. Among them, IL-1 is an important initiator for inflammation, which has an important role in IRI of multiple systems (5-7). Therefore, with IL-1 as an important entry point, the present study examined 
A

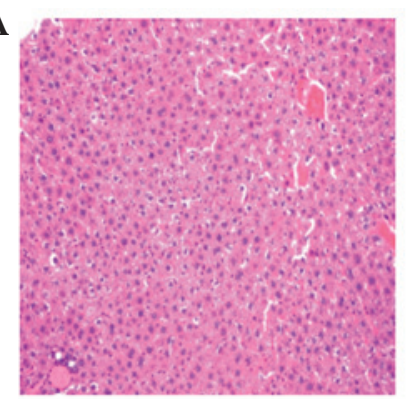

B

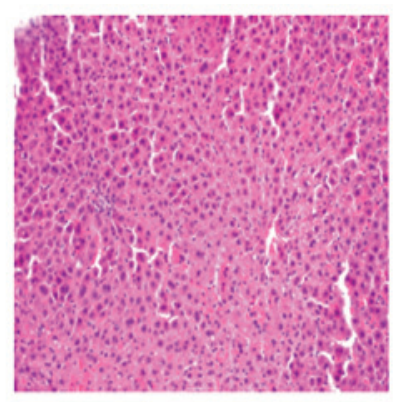

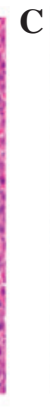
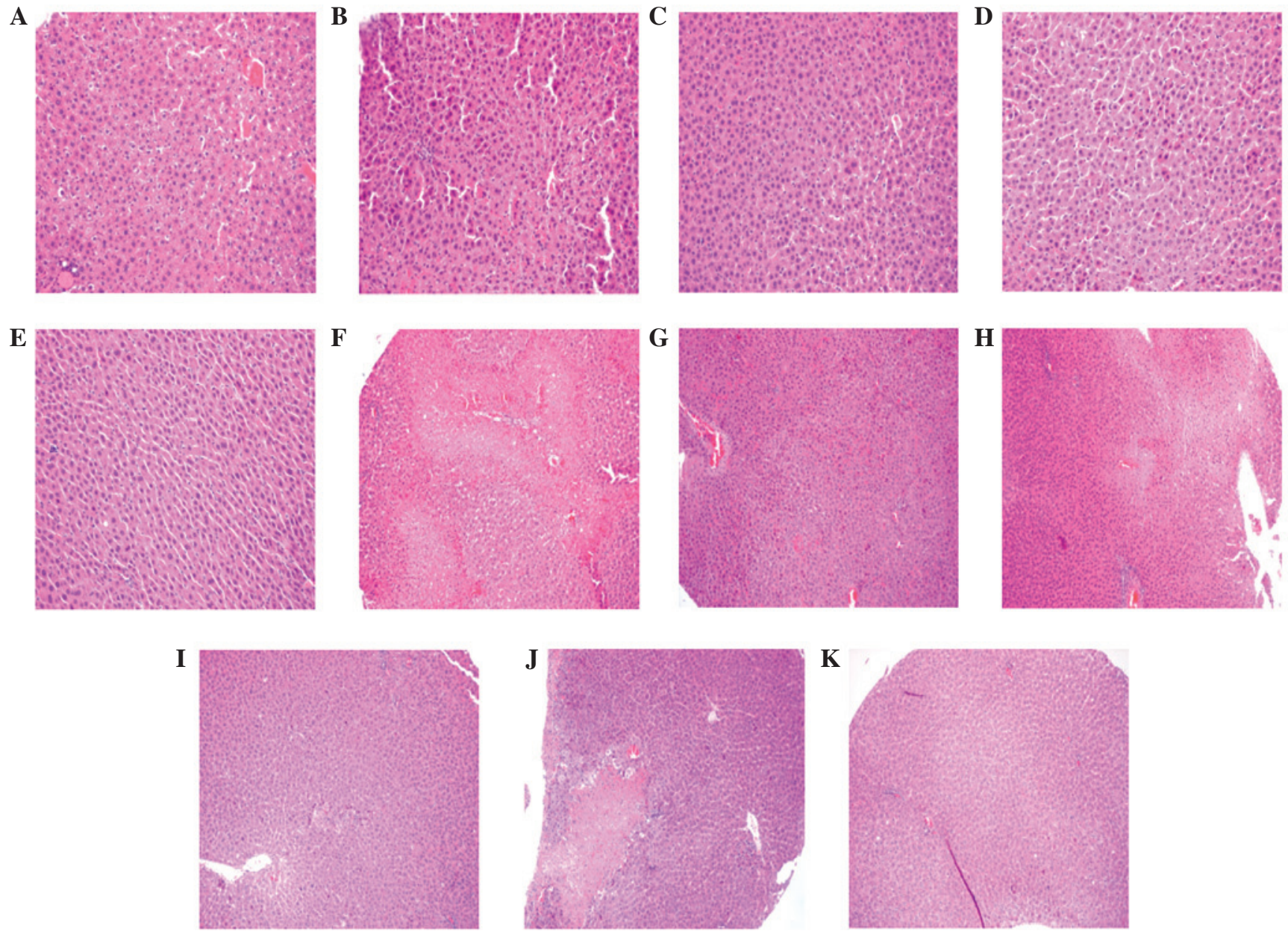

Figure 1. Hematoxylin and eosin (H\&E) staining of the different rat groups. H\&E staining results of the (A) normal rats, (B) 0 IR group, (C) 0 MT group, (D) $2 \mathrm{~h}$ IR group, (E) $2 \mathrm{~h} \mathrm{MT}$ group, (F) $4 \mathrm{~h} \mathrm{IR} \mathrm{group,} \mathrm{(G)} 4 \mathrm{~h}$ MT group, (H) $8 \mathrm{~h}$ IR group, (I) $8 \mathrm{~h}$ MT group, (J) $24 \mathrm{~h} \mathrm{IR} \mathrm{group} \mathrm{and} \mathrm{(K)} 24 \mathrm{~h} \mathrm{MT}$ group. [(A-E) magnification, x200; (F-K) magnification, x100]. MT, melatonin treatment; IR, ischemia reperfusion.

IL-1 expression prior and subsequent to reperfusion and MT intervention. The results showed that IL-1 $\beta$, the main active forms of IL-1, was evidently increased in IR rats. IL-1 $\beta$ was clearly higher at $35 \mathrm{~min}$ of ischemia and 2, 4, 8 and $24 \mathrm{~h}$ after reperfusion compared to IL-1 $\beta$ prior to HPO, and the most significant increase of IL- $1 \beta$ was at $8 \mathrm{~h}$ after reperfusion. Possible mechanisms causing the increase of IL- $1 \beta$ in liver IR included: Neutrophils, mononuclear macrophages, lymphocytes and endothelial cells, which secrete more IL-1 (8); liver cells can also express and synthesize IL-1 under ischemia and hypoxia stimulation $(9,10)$; other inflammatory factors, such as IL-6 and intercellular adhesion molecule-1, can also stimulate mononuclear macrophages and neutrophils to produce IL-1; and IL-1 itself can stimulate the synthesis and release of IL-1 for feedback $(11,12)$.

In the present study, it was found that IL-1 $\beta$ following IR was significantly higher compared to normal rats, as IL-1 is one of the initiators of inflammation. Blocking IL-1 can reduce the liver IRI $(13,14)$. Previous experiments on heart and kidneys have confirmed that IL-1 could be reduced and an inflammatory response could be initiated by directly administrating IL-1 receptor blockers or increasing the IL-1 receptor inhibition gene via gene transfection $(15,16)$. In addition, it can reduce IL-1 $\beta$-induced apoptosis (17). Therefore, if the excessive release of IL-1 can be inhibited following hepatic IR, IRI could be reduced. In the present study, rats treated by MT had significantly lower IL-1 $\beta$ at each time-point of reperfusion 35 min after HPO compared to the rats not treated by MT $(\mathrm{P}<0.05)$. MT can block a series of IL-1 $\beta$-mediated inflammatory reactions by reducing IL- $1 \beta$ in rat hepatic reperfusion, so as to reduce liver structure and function injury due to IR. Previous studies have shown that the nitric oxide (NO) gene was closely associated with the production of IL-1 in liver IR $(18,19)$, and MT was confirmed to effectively downregulate nuclear factor- $\mathrm{\kappa B}$ expression and inhibit the activity of inducible NO synthase in rat liver IR $(20,21)$, so as to moderately adjust NO generation. The latter was closely associated with the release of IL-1 $\beta$ (22). Therefore, MT may reduce the release of IL-1 $\beta$ by adjusting NO.

This is the most ideal method to reduce IRI by endogenous protective reaction to enhance the tolerance of the liver itself. IL-1 is one of the important regulatory factors for acute inflammation (23). IL-1Ra can inhibit the roles of IL-1 $\alpha$ and IL-1 $\beta$ through competitive combination with type I and II IL-1 receptors, thus reducing inflammation (24). Recombinant human (Rh) IL-1Ra was the first identified natural cytokine antagonists. It has a certain degree of homology with IL-1 $\alpha$ and IL-1 $\beta$ and it can competitively combine with type I and type II IL-1 receptors without producing IL-1-like effects. Animal studies showed that RhIL-1Ra can effectively block 
Table I. Changes of interleukin-1 $\beta$ activity in ischemia reperfusion injury rats.

\begin{tabular}{|c|c|c|c|c|c|c|}
\hline \multirow[b]{2}{*}{ Groups } & \multirow{2}{*}{$\begin{array}{l}\text { Normal } \\
\text { time-point, h }\end{array}$} & \multicolumn{5}{|c|}{ Reperfusion time, $\mathrm{h}$} \\
\hline & & 0 & 2 & 4 & 8 & 24 \\
\hline $\mathrm{N}$ & $17.68 \pm 4.78$ & - & - & - & - & - \\
\hline IR & - & $45.76 \pm 3.39^{a}$ & $50.22 \pm 7.81^{\mathrm{a}}$ & $61.40 \pm 10.76^{\mathrm{a}}$ & $62.77 \pm 15.05^{\mathrm{a}}$ & $57.45 \pm 16.98^{a}$ \\
\hline MT & - & $28.38 \pm 4.76^{\mathrm{a}, \mathrm{b}}$ & $30.47 \pm 3.56^{\mathrm{a}, \mathrm{b}}$ & $38.14 \pm 6.92^{\mathrm{a}, \mathrm{b}}$ & $37.03 \pm 6.59^{\mathrm{a}, \mathrm{b}}$ & $40.60 \pm 11.24^{\mathrm{a}}$ \\
\hline
\end{tabular}

Data are nmol/\%. Compared to agroup N, P<0.05; 'broups MT and IR, $\mathrm{P}<0.05$. N, normal; MT, melatonin treatment; IR, ischemia reperfusion.

A

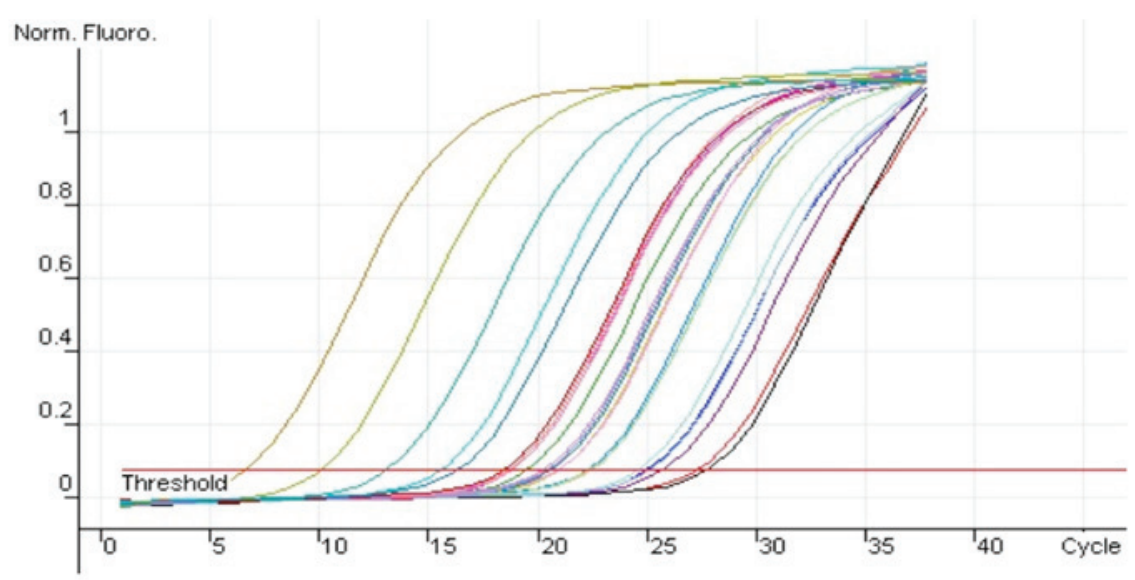

B
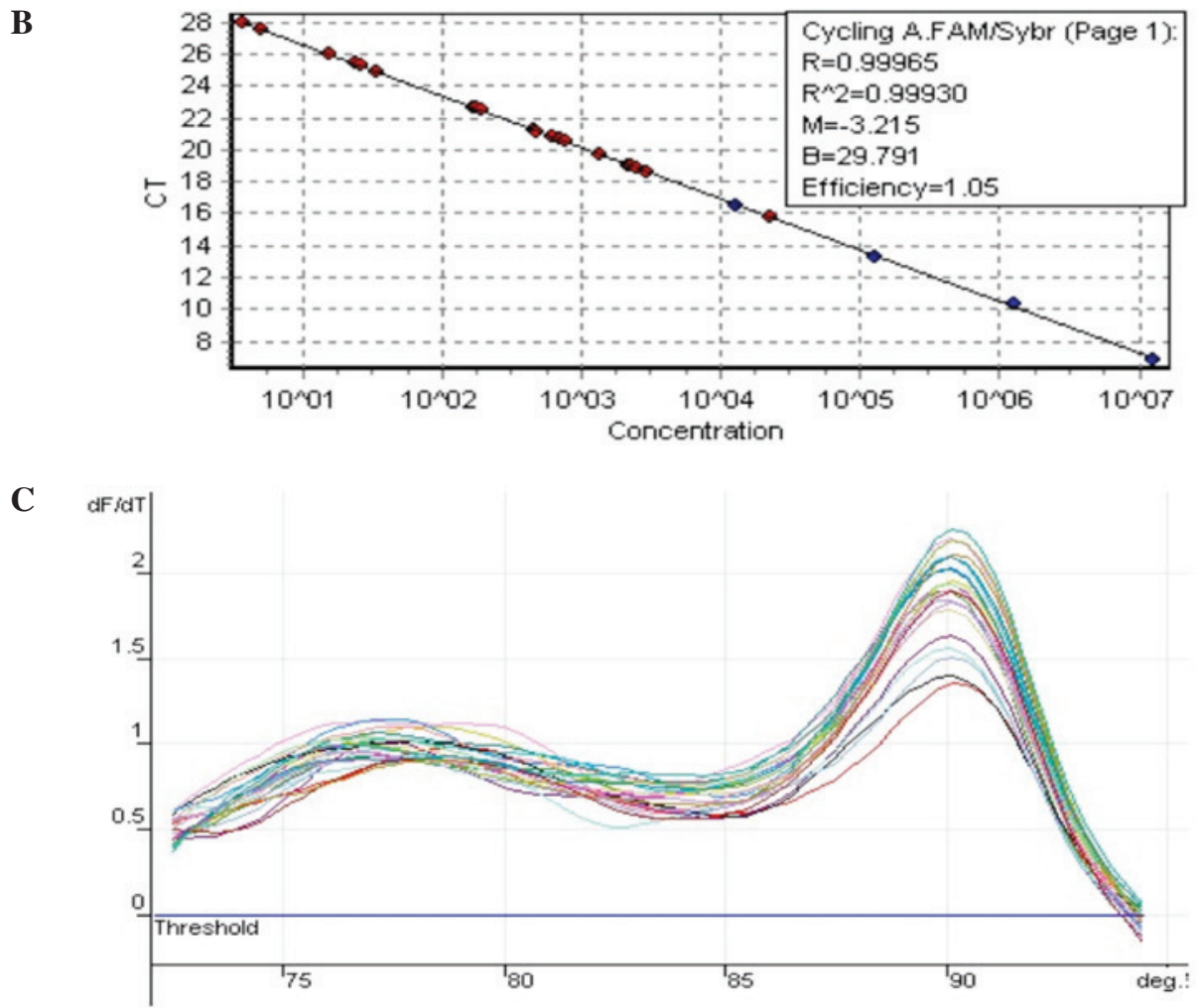

Figure 2. Expression of NM_022194 (interleukin-1 receptor antagonist). (A) Quantitation data for Cycling A.FAM/Sybr. (B) Standard curve. (C) Melting curve data for Melt A.FAM/Sybr.

the effect of IL-1, treat certain inflammatory diseases that were associated with the disorder of cytokines, and return the excessive IL-6 and tumor necrosis factor- $\alpha$ level to normal without interfering with the internal environment balance (25). RhIL-1Ra has been clinically trialed on rheumatoid arthritis and autoimmune disease, and has achieved good curative 
A

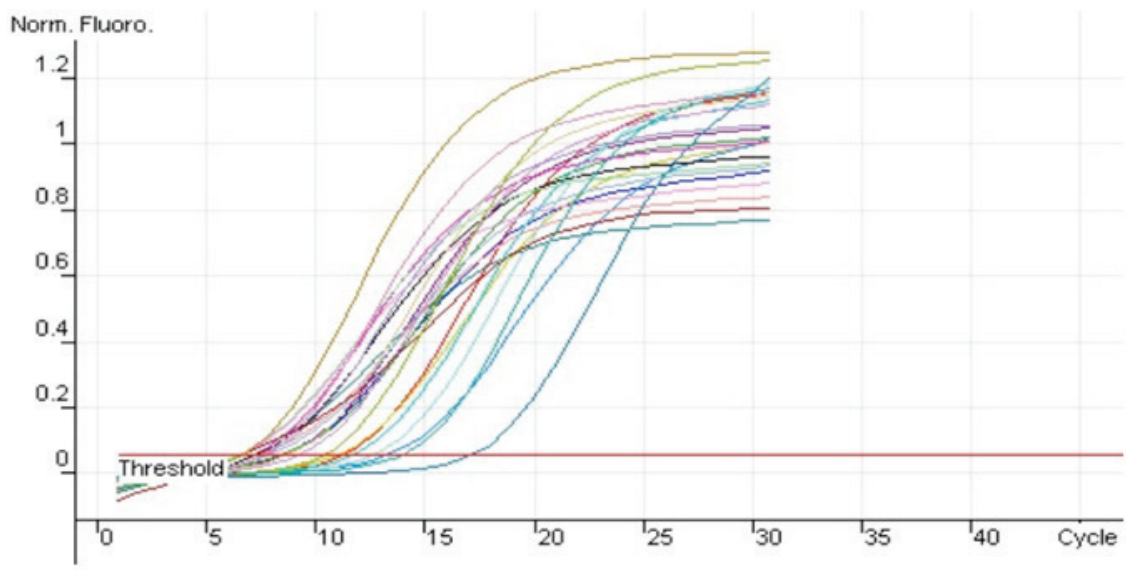

$\mathbf{B}$

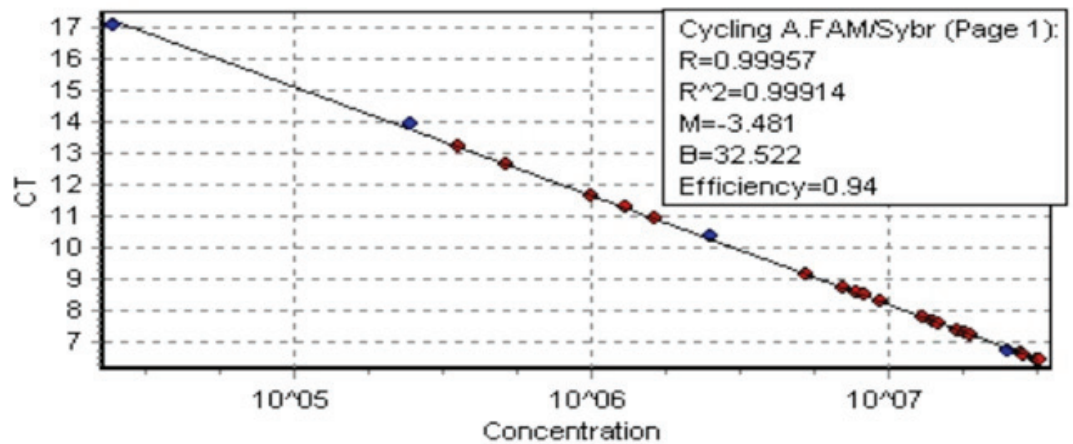

C

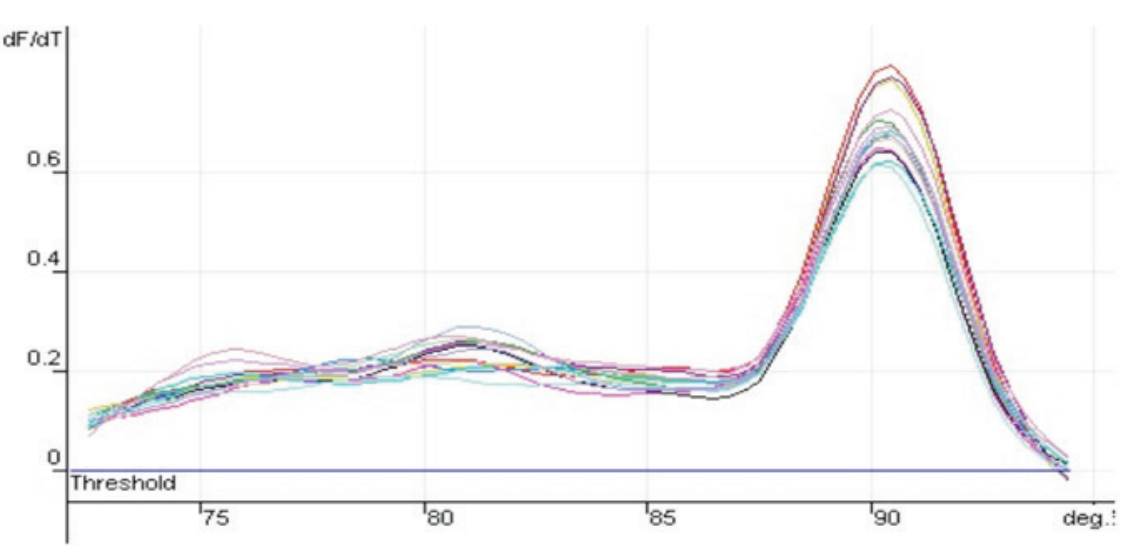

Figure 3. Expression of 18S. (A) Quantitation data for Cycling A.FAM/Sybr. (B) Standard curve. (C) Melting curve data for Melt A.FAM/Sybr.

Table II. Relative expression of IL-1Ra.

\begin{tabular}{lc}
\hline Groups & IL-1Ra \\
\hline MT0/IR0 & 0.456871016 \\
MT2/IR2 & 4.858945705 \\
MT4/IR4 & 9.342555162 \\
MT8/IR8 & 0.620242510 \\
MT24/IR24 & 0.992904616 \\
\hline
\end{tabular}

IL-1Ra, interleukin-1 receptor antagonist; MT, melatonin treatment; IR, ischemia reperfusion; $0,2,4,8$ and 24 , time (h) after reperfusion.

effects. No adverse effects have been identified in long-term application (26). Previous cardiac and renal experiments have confirmed that IL-1Ra expression, which is increased by the direct administration of IL-1 receptor blockers or gene transfection, can reduce the inflammatory response $(15,16)$. In addition, IL-1Ra can reduce IL-1 $\beta$-induced apoptosis (17). Therefore, if overexpression of IL-1Ra can be induced following liver IR, it would help to reduce IRI.

Therefore, the present study detected two groups of rat liver specimens, which were administered reperfusion $35 \mathrm{~min}$ after HPO and found that IL-1Ra genes, which were almost not detected in normal rats, were significantly increased. IL-1Ra expression in the $2 \mathrm{~h}$ MT group was higher than that of the IR group by 4-fold, and IL-1Ra expression in the $4 \mathrm{~h}$ MT group was higher than that of the IR group by 9-fold. Expression differences between the two groups at other time-points were all within 2-fold. Barrier et al (27) reported the upregulation of IL-1Ra in liver pretreated by ischemia with gene-chip 
technology. They believed that protective mechanisms of ischemic preconditioning on liver IRI were associated with overexpression of IL-1Ra. However, the mechanism of increased IL-1Ra following IR remains to be elucidated. In the present study, IL-1Ra in the group pre-treated by MT was 9-fold higher than that of IR following IR, and further experiments are required to prove whether MT can induce upregulation of IL-1Ra, similar to ischemic preconditioning, thus producing protective effects.

In conclusion, the present study suggested that MT can protect the liver and reduce IRI not only by reducing the production of IL-1, but also by blocking IL-1 receptors, namely raising IL-1Ra gene expression. As the serious side effects of MT have not been reported yet, this may be a new way for protecting IRI in clinical studies.

\section{References}

1. Li Y, Yang Y, Feng Y, Yan J, Fan C, Jiang S and Qu Y: A review of melatonin in hepatic ischemia/reperfusion injury and clinical liver disease. Ann Med 46: 503-511, 2014.

2. Liu LF, Qin Q, Qian ZH, Shi M, Deng QC, Zhu WP, Zhang H, Tao XM and Liu Y: Protective effects of melatonin on ischemia-reperfusion induced myocardial damage and hemodynamic recovery in rats. Eur Rev Med Pharmacol Sci 18: 3681-3686, 2014

3. Rodríguez-Reynoso S, Leal C, Portilla E, Olivares N and Muñiz J: Effect of exogenous melatonin on hepatic energetic status during ischemia/reperfusion: Possible role of tumor necrosis factor- $\alpha$ and nitric oxide. J Surg Res 100: 141-149, 2001.

4. Deprés-Brummer P, Metzger G, Morin D, Urien S, Touitou Y, Tillement JP, Claustrat B and Lévi F: Pharmacokinetically guided melatonin scheduling in rats with circadian system suppression. Eur J Pharmacol 312: 171-178, 1996

5. Simeoni E, Dudler J, Fleury S, Li J, Pagnotta M, Pascual M, von Segesser LK and Vassalli G: Gene transfer of a soluble IL-1 type 2 receptor-Ig fusion protein improves cardiac allograft survival in rats. Eur J Cardiothorac Surg 31: 222-228, 2007.

6. Sener G, Sehirli O, Velioğlu-Oğünç A, Cetinel S, Gedik N, Caner M, Sakarcan A and Yeğen BC: Montelukast protects against renal ischemia/reperfusion injury in rats. Pharmacol Res 54: 65-71, 2006.

7. Menger MD, Richter S, Yamauchi J and Vollmar B: Role of microcirculation in hepatic ischemia/reperfusion injury. Hepatogastroenterology 46 (Suppl 2): 1452-1457, 1999.

8. Galea J, Armstrong J, Gadsdon P, Holden H, Francis SE and Holt CM: Interleukin-1 beta in coronary arteries of patients with ischemic heart disease. Arterioscler Thromb Vasc Biol 16 1000-1006, 1996.

9. Deten A, Volz HC, Briest W and Zimmer HG: Cardiac cytokine expression is upregulated in the acute phase after myocardial infarction. Experimental studies in rats. Cardiovasc Res 55: 329-340, 2002

10. Herskowitz A, Choi S, Ansari AA and Wesselingh S: Cytokine mRNA expression in postischemic/reperfused myocardium. Am J Pathol 146: 419-428, 1995.

11. Neumann FJ, Marx N, Gawaz M, Brand K, Ott I, Rokitta C, Sticherling C, Meinl C, May A and Schömig A: Induction of cytokine expression in leukocytes by binding of thrombinstimulated platelets. Circulation 95: 2387-2394, 1997.
12. Prabhu SD, Chandrasekar B, Murray DR and Freeman GL: beta-adrenergic blockade in developing heart failure: Effects on myocardial inflammatory cytokines, nitric oxide, and remodeling. Circulation 101: 2103-2109, 2000.

13. Hashimoto K, Nishizaki T, Yoshizumi T, Uchiyama H, Okano S, Ikegami T, Yanaga K and Sugimachi K: Beneficial effect of FR167653 on cold ischemia/reperfusion injury in rat liver transplantation. Transplantation 70: 1318-1322, 2000

14. Kobayashi J, Takeyoshi I, Ohwada S, Iwanami K, Matsumoto K, Muramoto M and Morishita Y: The effects of FR167653 in extended liver resection with ischemia in dogs. Hepatology 28: 459-465, 1998

15. Harada H, Wakabayashi G, Takayanagi A, Shimazu M, Matsumoto K, Obara H, Shimizu N and Kitajima M: Transfer of the interleukin-1 receptor antagonist gene into rat liver abrogates hepatic ischemia-reperfusion injury. Transplantation 74: 1434-1441, 2002.

16. Suzuki K, Murtuza B, Smolenski R, Sammut IA, Suzuki N, Kaneda Y and Yacoub MH: Overexpression of interleukin-1 receptor antagonist provides cardio protection against ischemiareperfusion injury associated with reduction in apoptosis. Circulation 104 (Suppl 1): 308-313, 2001.

17. Maedler K, Sergeev P, Ehses JA, Mathe Z, Bosco D, Berney T, Dayer JM, Reinecke M, Halban PA and Donath MY: Leptin modulates beta cell expression of IL-1 receptor antagonist and release of IL-1beta in human islets. Proc Natl Acad Sci USA 101: 8138-8143, 2004.

18. Kohli V, Gao W, Camargo CA Jr and Clavien PA: Calpain is a mediator of preservation-reperfusion injury in rat liver transplantation. Proc Natl Acad Sci USA 94: 9354-9359, 1997.

19. Li SQ, Liang LJ, Huang JF and Li Z: Ischemic preconditioning protects liver from hepatectomy under hepatic inflow occlusion for hepatocellular carcinoma patients with cirrhosis. World J Gastroenterol 10: 2580-2584, 2004.

20. Hur GM, Ryu YS, Yun HY, Jeon BH, Kim YM, Seok JH and Lee JH: Hepatic ischemia/reperfusion in rats induces iNOS gene transcription by activation of NF-kappaB. Biochem Biophys Res Commun 261: 917-922, 1999.

21. Xiong S, She H, Takeuchi H, Han B, Engelhardt JF, Barton CH, Zandi E, Giulivi $\mathrm{C}$ and Tsukamoto $\mathrm{H}$ : Signaling role of intracellular iron in NF-kappaB activation. J Biol Chem 278: 17646-17654, 2003.

22. Koeppel TA, Thies JC, Schemmer P, Trauner M, Gebhard MM, Otto $\mathrm{G}$ and Post $\mathrm{S}$ : Inhibition of nitric oxide synthesis in ischemia/reperfusion of the rat liver is followed by impairment of hepatic microvascular blood flow. J Hepatol 27: 163-169, 1997.

23. Raz R, Durbin JE and Levy DE: Acute phase response factor and additional members of the interferon-stimulated gene factor 3 family integrate diverse signals from cytokines, interferons, and growth factors. J Biol Chem 269: 24391-24395, 1994.

24. Gabay C, Smith MF, Eidlen D and Arend WP: Interleukin 1 receptor antagonist (IL-1Ra) is an acute-phase protein. J Clin Invest 99: 2930-2940, 1997.

25. Pang SF, Dubocovich ML and Brown GM: Melatonin receptors in peripheral tissues: A new area of melatonin research. Biol Signals 2: 177-180, 1993.

26. Ding WH, Wu FX and Li DY: The change of plasma interleukin-6 level and cardiac protective effect of monoclonal antibody to IL-6 during myocardial infarction. Zhonghua Xin Xue Guan Bing Za Zhi 27: 29-32, 1999 (In Chinese).

27. Barrier A, Olaya N, Chiappini F, Roser F, Scatton O, Artus C, Franc B, Dudoit S, Flahault A, Debuire B, et al: Ischemic preconditioning modulates the expression of several genes, leading to the overproduction of IL-1Ra, iNOS, and Bcl- 2 in a human model of liver ischemia-reperfusion. FASEB J 19: 1617-1626, 2005. 